\title{
DAS ESTRELAS QUE NÃO VEMOS: CONCEITO, FEMINISMO E POLUIÇÃO LUMINOSA
}

\author{
STARS THAT WE DON'T SEE: CONCEPT, FEMINISM AND LIGH POLLUITION
}

Jamile Wayne Ferreira ${ }^{1}$

\begin{abstract}
Resumo
O presente artigo visa debater sobre os caminhos epistemológicos do feminismo, pensando a palavra, os conceitos e significados que circundam a ideia de feminismo. Considerando que o feminismo, ao longo do tempo, foi sendo definido a partir de práticas hegemônicas e reproduzindo racionalidades, é muito importante pensar a partir de outras perspectivas. Dessa forma, como movimento educador, muitas vezes reproduz as lógicas de dominação que se entrecruzam e retroalimentam, como a lógica do capital, patriarcal e da colonialidade, o que se caracteriza pela ideia que centra o movimento feminista na experiência datada de mulheres europeias, que embora tenham sido importantes para o movimento e a teoria feminista, não são o centro da luta das mulheres. Nesse sentido, é de suma importância olhar para o céu feminista como um céu que contém estrelas que, embora existam e (re)existam, são postas à margem do firmamento, na sua historicidade, prática e conceituação. Assim, as estrelas que não enxergamos nesse céu são avistadas a partir da reflexão sobre conceito, feminismo e poluição luminosa, categorias, aqui, atravessadas pela perspectiva decolonial, na busca de compreender o feminismo além de parâmetros hegemônicos e de perceber na experiência de mulheres do Sul uma agência de luta e movimento histórico.
\end{abstract}

Palavras-chave: Educação; Feminismo; Decolonialidade.

\begin{abstract}
This article aims to debate the epistemological ways of feminism, thinking about the word, concepts and meanings that surround the idea of feminism. Considering that feminism, historially, was defined based on hegemonic practices and reproducing rationalities, is very important to think from that others perspectives. In this way, as an educating movement, it often reproduces the logics of domination that intertwine and feed back, such as the logic of capital, patriarchy and coloniality, which is characterized by the idea that centers the feminist movement on the dated experience of European women, who, although important for the movement and feminist theory, are not the center of the women's struggle. In this sense, it is extremely important look of the feminist sky as a sky that contains stars that, although they exist and (re)exist, are placed on the margins of the firmament, in their historicity, practice and conceptualization. Thus, the stars that we don't see in this sky are seen from the reflection on concept, feminism and light pollution, categories, here, crossed by the decolonial perspective, in the search to understand feminism
\end{abstract}

Faculdade de Educação, Universidade Federal de Pelotas (UFPel), Pelotas/RS, Brasil. e-mail: milewayne.gastronomia@gmail.com ORCID: http://orcid.org/0000-0003-4864-5417 (autor correspondente) 
beyond hegemonic parameters and to perceive in the experience of women from South an agency of struggle and historical movement.

Keyword: Education; Feminism; Decoloniality.

\section{Introdução}

A obra "a noite estrelada", de Vincent van Gogh, é o que ilustra a capa do livro de José D’assunção de Barros (2016), que se propõe a pensar como operam os conceitos nas ciências humanas. De acordo com o autor, "mesmo os campos de saber e de práticas que ainda se debatem acirradamente na luta por se verem reconhecidos no panteão das ciências, ou que nunca tiveram tal pretensão, valem-se de conceitos" (BARROS, 2016, p.10). Como "patamar de reflexão inicial", faz uso da Astronomia, pois, de acordo com o autor, "foi para organizar o céu - para tornálo mais familiar e compreensível, mas apreensível e assimilável, e, eventualmente, mais previsível - que surgiram os primeiros conceitos da Astronomia" (BARROS, 2016, p. 14). Pensar o céu também pode ser útil para refletir sobre o que este presente trabalho busca discutir, através das ideias a respeito dos conceitos, questões pertinentes ao movimento feminista e sua práxis educativa.

O presente artigo possui o objetivo de refletir sobre os caminhos epistemológicos e de compreensão do feminismo. Para isso, num primeiro momento reflete sobre os conceitos em si, depois passa a discutir a ideia de um feminismo que apresenta um centro irradiador, portanto, produzindo margens, discutindo categorias como mulher e gênero. Na última parte, se propõem a articular a ideia de um feminismo decolonial como caminho rompante para os ofuscamentos produzidos pelo pensamento hegemônico feminista.

Se para Barros (2016), “os conceitos ajudam os historiadores e cientistas sociais a organizarem o céu (ou o inferno) que pretendem examinar" (BARROS, 2016, p.23), coloco em dúvida se o céu que observamos reflete a luz de todas as estrelas que nele habitam. De acordo com Gargaglioni (2009), existem três tipos de poluição luminosa que nos impedem de observar o céu tal qual ele é, o brilho no céu, o ofuscamento e a luz intrusa. A respeito disso, o autor destaca que:
Com o crescimento das cidades tem ocorrido o aumento do brilho no céu noturno na maioria dos países. Esse efeito reduz a visibilidade das estrelas, além de causar muitos outros impactos. O aumento na luminosidade do céu noturno é um dos efeitos mais evidentes da poluição luminosa, que pode ser definida como a luz externa mal-direcionada que não é aproveitada devidamente, causando o brilho visto acima das cidades, ao invés de somente iluminar o chão (GARGAGLIONI, 2009, p.1).

Nesse sentido, pensar a luta das mulheres dentro da História da humanidade é se debruçar sob um céu imenso e poluído, seja por brilho em excesso, ofuscamentos ou intrusões, onde é preciso não ler as estrelas, mas os entre espaços delas. E isso se reflete nas interpretações feitas a partir do feminismo, que reproduz essa racionalidade ao passo que coloca o feminismo não hegemônico em outros patamares interpretativos, muitas vezes sem nem mesmo entender lutas, experiência e vivências de mulheres fora do centro reprodutor do ser, saber e poder como feminismo. De acordo com o Barros (2016), os conceitos surgiram por necessidade da humanidade. Para ele, essa "vontade de conceito",

não se tratava apenas de nomear as coisas, hábito já antigo entre os seres humanos quando davam curso aos seus processos de comunicação, mas de compreender com mais precisão as características de cada fenômeno ou objeto - de forma muito bem delineada - e, ato contínuo, de agrupar os casos específicos em categorias maiores, as quais deveriam ser elaboradas tendo em vista todas as suas implicações e possibilidades de relações e contrastes 
umas com as outras (BARROS, 2016, p.14).

É fundamental, primeiro, entender as importantes contribuições do autor sobre como operam os conceitos. Segundo Barros, é através dos conceitos que conseguimos «enfrentar a estonteante velocidade com a qual todas as coisas se dissipam» (BARROS, 2016, p.35). Dessa maneira, é através dos conceitos que conseguimos comunicar, organizar, generalizar, comparar, problematizar e aprofundar uma ideia. Dentre alguns exemplos trazidos pelo autor no decorrer do livro, vou me concentrar em um e a partir dele pensar como se articulam a ideia de feminismo atualmente. Para Barros (2016),

Feminismo, em contrapartida, é um conceito de baixo "potencial generalizador diacrônico". É daqueles conceitos que, uma vez cunhado, parece sempre aplicável ao próprio período para o qual foi imaginado originalmente. O feminismo é um fenômeno social que tem a sua origem datada (do fim, ainda não sabemos, mas supõe-se que ocorrerá quando desaparecer o par antagônico que o gerou como resistência, o "machismo"). $\mathrm{O}$ conceito de feminismo, surgido nas últimas décadas do século XIX, mas consolidado e intensificado em sua aplicação a partir do século XX, não parece ser aplicado a outros momentos históricos (anteriores ao momento em que esse conceito surgiu). Pode ser aplicável para tempos futuros, desde que as sociedades vindouras o atualizem com suas práticas) (BARROS, 2016, p.168).

É preciso entender o que o autor entende como «potencial generalizador diacrônico». Para Barros, ter um potencial generalizador é um pressuposto de todo conceito, mas por diacrônico caracteriza aqueles que além desse potencial, atravessam momentos distintos da história. O feminismo, para o autor, é um conceito datado a partir de uma leitura histórica que faz. O dicionário Michaelis apresenta a etimologia da palavra feminismo como derivada do latim feminna+ismo, do francês féminisme. Define o feminismo da seguinte maneira:

Movimento articulado na Europa, no século XIX, com o intuito de conquistar a equiparação dos direitos sociais e políticos de ambos os sexos, por considerar que as mulheres são intrinsecamente iguais aos homens e devem ter acesso irrestrito às mesmas oportunidades destes. (O movimento pressupunha, já de início, uma condição fundamental de desigualdade, tanto em termos de dominação masculina, ou patriarcado, quanto de desigualdade de gênero e dos efeitos sociais decorrentes da diferença sexual.) (FEMINISMO, 2021).

No Dicionário Crítico de Gênero, "feminismofeminismos" é um conceito definido por Maria Elizabeth Ribeiro Carneiro (2019), como "fenômeno social, cultural que assume feições específicas de acordo com o lugar e os sujeitos que dele ou nele falam" (p.251). Embora reconheça que o feminismo é definido historicamente por balizas que foram registradas e reconhecidas dentro da historiografia, a autora faz o uso do "s" para reconhecer "o conjunto diverso de experiências e acepções possíveis que remetem ao enunciado" (CARNEIRO, 2019, p. 254). Maria Odila Leite da Silva Dias (1994), destaca a importância dos estudos feministas no processo de reelaboração dos métodos das ciências humanas. De acordo com a autora:

Os estudos feministas propõem uma redefinição dos processos de subjetividade, uma crítica ao conceito da própria racionalidade no mundo contemporâneo, que se volta para o passado a fim de se reencontrar, devidamente relativizada, no presente [...] impõe-se a necessidade de documentar a experiência vivida como possibilidade de abrir caminhos novos [...] o conhecimento histórico dessas identidades femininas até hoje desconhecidas seria um passo na 
construção de subjetividades plurais (DIAS, 1994, p. 375).

Além disso, cabe ressaltar a importância das articulações do feminismo para se pensar a sociedade como um todo, como destaca Miguel (2015), pois “[...] ao denunciar a situação das mulheres como efeito de padrões de opressão, o pensamento feminista caminhou para uma crítica ampla do mundo social, que reproduz assimetrias e impede a ação autônoma de muitos de seus integrantes" (MIGUEL, 2015, p.17). Dessa forma, o autor destaca a relevância dos estudos feministas para a teoria política. Para ele,

O debate sobre a dominação masculina nas sociedades contemporâneas ou o "patriarcado", como preferem algumas - abriu portas para tematizar, questionar e complexificar as categorias centrais por meio das quais era pensado o universo da política, tais como as noções de indivíduo, de espaço público, de autonomia, de igualdade, de justiça ou de democracia (MIGUEL, 2015, p.17).

Dentro das interpretações de feminismos, existe a ideia de que "[...] o feminismo, em suas várias vertentes, combina a militância pela igualdade de gênero com a investigação relativa às causas e aos mecanismos de reprodução da dominação masculina" (MIGUEL, 2015, p.17). É comum, no pensamento hegemônico, a ideia de uma raiz feminista. Para Miguel (2015),

O feminismo se definiu pela construção de uma crítica que vincula a submissão da mulher na esfera doméstica à sua exclusão da esfera pública. Assim, no mundo ocidental, o feminismo como movimento político e intelectual surge na virada do século XVIII para o século XIX e pode ser considerado um filho indesejado da Revolução Francesa (MIGUEL, 2015, p. 18).

Se dentro do conceito de feminismo não se reconhece as inúmeras experiências de mulheres em variados contextos e momentos históricos como forma de articulação contra o meio opressor, ou seja, a sociedade patriarcal, pode ser pela possibilidade de que um conceito "parece sempre visar à realidade, mesmo que sem assegurar a possibilidade de apreendê-lo total ou parcialmente; ou, em uma metade lógica dos casos, mesmo que sem ter sequer a pretensão efetiva de apreender a realidade tal como ela é" (BARROS, 2016, p.19), mas, para o autor, isso não nos impede que visá-la. De acordo com Dias (1994),

[...] para apreender no passado estes momentos de resistência é preciso uma formação crítica do historiador (a) que enseje a elaboração de conceitos temporalizados e a vontade de perseguir abordagens teóricas necessariamente parciais, pois o saber teórico implica também um sistema de dominação. (DIAS, 1994, p. 375).

Dessa forma, há uma leitura epistemológica do conceito de feminismo, que embora tenha se esforçado para apreender a realidade, por sua natureza epistemológica, não a capturou tal qual ela é ou foi.

\section{Entre caminhos para margem}

Para Yuderkys Espinosa Miñoso (2020), os feminismos, dentro de todas as suas variantes e posicionamentos, "foi capaz de compartilhar a história de uma origem comum e certas convicções ou princípios fundamentais que derivam dessa história" (MIÑOSO, 2020, p.3). O que o feminismo com a perspectiva decolonial faz, de acordo com ela, é avançar na medida que põe em dúvida a unidade "das mulheres" e o horizonte para o qual se olha a partir da ideia de modernidade. Para a autora:

[...] o feminismo em sua cumplicidade com a aposta decolonial toma para si a tarefa de reinterpretação da história em chave crítica da modernidade, já não apenas por seu androcentrismo e misoginia, como tem feito a epistemologia feminista clássica, mas também dado o seu caráter 
intrinsicamente racista e eurocêntrico [...] não apenas nos opomos à pretensão salvacionista do feminismo em sua forma clássica, mas podemos demonstrar como essa herança colonial é perversa (MIÑOSO, 2020, p.5).

Joana Maria Pedro (2011), recaptura a história do feminismo, de acordo com ela, "tem sido uma narrativa hegemonicamente definida pelo hemisfério norte" (PEDRO, 2011, p. 271). Além disso, a autora chama a atenção para a ideia de que,

Pensar o feminismo a partir de diferentes ondas reforça a ideia da existência de centros irradiadores e suas margens; como se uma pedra tivesse sido atirada na água, formando várias ondas. Elas vão se abrindo e apontando para a circulação de discursos e teorias que partem de um centro produtor - em geral, países considerados desenvolvidos do hemisfério norte - e se dirigem para o hemisfério sul, localização principal dos países considerados subdesenvolvidos (PEDRO, 2011, p. 271).

A ideia das ondas é uma forma de dividir as pautas feministas em épocas. Para Miguel (2015), "o programa dessa primeira fase do feminismo tinha como eixos a educação das mulheres, o direito ao voto e a igualdade no casamento, em particular o direito das mulheres casadas a dispor de suas propriedades" (MIGUEL, 2015, p. 18). Contudo, conforme Joana Maria Pedro (2011), as pautas das tais “ondas", de acordo com o campo historiográfico, acontecem com atraso nos países do Cone Sul. Diferente dessa perspectiva, a leitura do feminismo através das lentes que articulam as discussões entre gênero e colonialidade, permite que brilhem outras estrelas no céu feminista. Dentro dessa concepção, “a partir das margens, e não a partir do 'centro', é possível ler melhor o mundo e, assim, elaborar um projeto crítico e transformador, com uma nova visão de mundo" (PEDRO, 2011, p.275).

Joana Maria Pedro (2011), também, observa que dentro das ondas feministas, categorias foram sendo enfatizadas ao longo da história e a partir dessas categorias podemos compreender 0 feminismo como emergindo sob formas distintas em diferentes lugares do planeta. É o caso da categoria mulher, pois em "diferentes países do Cone Sul, a História das Mulheres [...] encontra-se em diversas temporalidades, nunca seguindo as marcas temporais das "ondas", nem mesmo com atraso" (PEDRO, 2011, p.272). Em 1851, o discurso de Sojourner Truth já questionava o conceito de mulher,

Aqueles homens ali dizem que as mulheres precisam de ajuda para subir em carruagens, e devem ser carregadas para atravessar valas, e que merecem o melhor lugar onde quer que estejam. Ninguém jamais me ajudou a subir em carruagens, ou a saltar sobre poças de lama, e nunca me ofereceram melhor lugar algum! E não sou uma mulher? Olhem para mim? Olhem para meus braços! Eu arei e plantei, e juntei a colheita nos celeiros, e homem algum poderia estar à minha frente. E não sou uma mulher? Eu poderia trabalhar tanto e comer tanto quanto qualquer homem - desde que eu tivesse oportunidade para isso - e suportar o açoite também! E não sou uma mulher? Eu pari 3 treze filhos e vi a maioria deles ser vendida para a escravidão, e quando eu clamei com a minha dor de mãe, ninguém a não ser Jesus me ouviu! E não sou uma mulher? (TRUTH, 1851).

Dessa forma, pensar o feminismo como um fato histórico datado pode nos levar para um caminho excludente dentro da História das Mulheres. Para Françoise Vergès (2020), o que explica a reaproximação do termo "feminismo" de suas teorias e práticas apoia-se na "consciência de uma experiência profunda concreta e cotidiana de uma opressão produzida pela matriz Estado, patriarcado e capital, que fabrica a categoria "mulheres" para legitimar as políticas de reprodução e de categorização, ambas racializadas" (VERGÈS, 2020, p.51). A autora chama a atenção para vertentes do feminismo que visam inserir as mulheres em lógicas hegemônicas e que reproduzem os meios opressores dominantes, nomeia isso de feminismo civilizatório. 
Da mesma forma, o chamado 'feminismo liberal', que surgiu no século XVIII, mas desenvolveu-se ao longo do século XIX, tendo Wollstonecraft e Stuart Mill como principais expoentes, é marcado pelo seu evidente viés de classe. É de Stuart Mill, por exemplo, a afirmação de que "cuidar da casa não é uma verdadeira ocupação, pois 'não significa nada mais do que comprovar que os criados cumpram seu dever"' (MIGUEL, 2015, p.19). Uma afirmação que demonstra não apenas uma posição de classe privilegiada, mas uma leitura a respeito do que é trabalho e de como se entendia os trabalhos que reproduziam a vida, como os de cuidado.

De outra forma, o século XIX foi palco, também, de uma luta feminista que vinculava as questões da opressão de classe e gênero, como o caso de Flora Tristan que "fez da mulher trabalhadora um dos eixos centrais de seu tratado socialista utópico" (MIGUEL, 2015, p.20). Contudo, a radicalidade que essa corrente propunha fez com que o movimento feminista socialista ficasse à margem das pautas dominantes do feminismo hegemônico da época. De acordo com Guimarães (2005), “as feministas socialistas combinam as duas análises: o marxismo, com seu método histórico e materialista, e o feminismo radical, com sua compreensão das relações patriarcais, para conformar as teorias do feminismo socialista" (GUIMARÃES, 2005, p.87).

Para Maria de Fátima Guimarães (2005), o feminismo socialista "segue a tradição marxista, mas reconhece que as categorias econômicas do marxismo não são suficientes para entender e explicara opressão da mulher" (GUIMARÃES 2005, p. 87). De fato, dentro do pensamento de Marx e Engels é questionável a presença de uma pauta que se pusesse a pensar e articular a situação das mulheres com a complexidade merecida. Isso não significa que a igualdade de gênero não estivesse dentro de suas narrativas, mas a opressão das mulheres seguiu uma hermenêutica de "subproduto da dominação burguesa” (MIGUEL, 2015, p.20). Contudo, vale destacar a importância da obra de Engels para "vincular a organização da esfera doméstica à sociedade mais ampla" (MIGUEL, 2015, p.20), pois a dicotomia dessas esferas cria e reforça não apenas a divisão sexual de trabalho, mas as subjetividades entre os sexos. Para Guimarães (2005),

Esta repartição entre lugar de morar e lugar de trabalhar refletia a separação entre a produção social e a reprodução dos seres humanos. O espaço público e o da produção, o privado e o da reprodução humana, passaram a ser também, respectivamente, os espaços específicos de homens e de mulheres (GUIMARÃES, 2005, p. 81).

A autora chama atenção, também, para a forma com que o trabalho exercido no âmbito privado e reprodutivo não foi valorizado nem a partir da sua importância para a manutenção da sociedade, nem como produtor de força de trabalho, o que aproxima esse víes do feminismo liberal de Stuart Mill citado acima. Se para Federici (2019), "a condição não remunerada do trabalho doméstico tem sido a arma mais poderosa no fortalecimento do senso comum de que o trabalho doméstico não é trabalho" (FEDERICI, 2019, p. 43), para Guimarães (2005),

\begin{abstract}
Não podemos perder de vista que um dos fatores mais importantes nascidos do sistema da Revolução Industrial foi o domínio do trabalho-mercadoria, que se materializou na fábrica, ao contrário do trabalho-utilidade, sem valor de troca, toda via indispensável à reprodução da força de trabalho realizado na casa - este foi o quinhão que coube às mulheres nessa nova forma da antiga divisão sexual do trabalho (GUIMARÃES, 2005, p.81).
\end{abstract}

Uma figura que representa para o feminismo um símbolo de sua "raiz", e povoa o imaginário sobre o que é um pensamento feminista, é Simone de Beauvoir. Para Miguel (2015), o livro Segundo Sexo, de autoria dela, "representou uma tentativa poderosa de entender a construção social do 'feminino' como um conjunto de determinações e expectativas destinado a cercear a capacidade de agência autônoma das mulheres" (MIGUEL, 2015, p.22). No entanto, o autor destaca a importância epistemológica de Beauvoir que "abriu caminho para a discussão de uma epistemologia feminista distinta da epistemologia dominante, masculina" (MIGUEL, 2015, p.22). Nesse sentido, o autor destaca a importância da experiência como caminho do feminismo, onde "o conhecimento feminista seria 
marcado pela valorização da experiência vivida dos sujeitos sociais" (MIGUEL, 2015, p.22). E esta experiência, que pode ser muito diferente a depender do contexto histórico a que se está inserido, é o que mais interessa aqui.

Maria Odila Leite da Silva Dias (1994) chama atenção para o fato de que é preciso temporalizar os conceitos, para que "possam servir de balizas instáveis, porém críticas, renegados todas e quaisquer categorias universais, abandonadas quaisquer parâmetros fixos ou permanentes", pois, para ela, são posturas teóricas que vão se construído a partir de um processo de conhecimento "movediço num mundo transitório" (DIAS, 1994, p. 376).

Além da categoria mulher, os estudos de gênero também representam um marco nas discussões feministas. De acordo com Joana Maria Pedro (2011), em 1986 Joan Scott publicou nos Estados Unidos o que viria a ser traduzido no Brasil em 1990: Gênero, uma categoria útil de análise história. $\mathrm{O}$ olhar sob o gênero como um elemento constitutivo de relações sociais e as diferenciações entre os sexos como um primeiro passo simbólico entre relações de poder é a ideia central de Scott. Além disso, para a autora, a História não é apenas meio de registro, mas de uma narrativa não neutra e sobre a trajetória dos homens. Dessa forma, produz a diferença sexual e constrói gênero. Conforme Joana Maria Pedro (2011),

A história, nesse caso, é uma narrativa sobre sexo masculino e constitui o gênero ao definir que somente, ou principalmente, os homens fazem história. Além disso, falar de gênero significa deixar de focalizar a "mulher" ou as "mulheres"; tratava-se de relações entre homens e mulheres, mas também entre mulheres e entre homens. Nessa relação, o gênero se constituiria (PEDRO, 2011, p.273).

De acordo com Maria de Fátima Guimarães (2005), "[...] o conceito de gênero em seu uso mais recente, como instrumento de análise, ainda não tem espaços nos dicionários [...] formulado na academia na década de 1970, é historicamente fruto do movimento feminista contemporâneo" (GUIMARÃES, 2005, p.77). Conforme a autora, reside na ideia de gênero a compreensão de que,
[...] a mulher e o homem são construídos socialmente, a partir de uma cultura historicamente situada no tempo e dentro das circunstâncias possíveis, determinadas por essa temporalidade. Sujeitos de seu tempo, imersos em um conjunto específico de relações sociais historicamente situadas, cada ser-mulher e cada ser-homem têm um grupo originário e estão submetidos às regras de comportamento que se firmam conforme a ética hegemônica. Assim sendo, sob o ponto de vista da construção de sua especificidade de mulher e de homem, são determinantes sua classe, raça, religião e a forma de inserção na sociedade. Deste modo, a partir dessas variáveis fundamentais se constroem o ser-mulher e o serhomem (GUIMARÃES, 2005, p. 90).

A discussão sobre gênero avança muito mais, com diversas autoras que se propõem a pensar os limites e as possibilidades do conceito. A própria categoria mulher retoma dentro das discussões feministas com novas abordagens, mas o que quero me centrar aqui é na possibilidade de entender o feminismo além da narrativa histórica eurocentrada. Tendo em vista que a própria história das mulheres é um tema muito sensível dentro da história, como podemos afirmar que o feminismo é um movimento datado? Gloria Anzaldúa explora uma percepção mais porosa da história, ao se colocar em fronteiras, segundo sua própria explicação:

Comecei a pensar: Sim, sou chicana, mas isso não define quem eu sou. Sim, sou mulher, mas isso também não me define. Sim, sou lésbica, mas isso não define tudo o que sou. Sim, venho da classe proletária, mas não sou mais da classe proletária. Sim, venho de uma mestiçagem, mas quais partes dessa mestiçagem que se tornam privilegiadas? Só a parte espanhola, não a indígena ou negra. Comecei a pensar em termos de conciência mestiça. O que acontece com gente como eu que está ali no 
entre-lugar de todas essas categorias diferentes? O que é que isso faz com nossos conceitos de nacionalismo, de raça, de etnia, e mesmo de gênero? Eu estava tentando articular e criar uma teoria de existência nas fronteiras [...] (ANZALDÚA, apud PEDRO, 2011, p. 275).

Para Joana Maria Pedro (2011), o pensamento de Glória Anzaldúa "caminha no sentido contrário ao da noção de 'ondas' [...] aos quais partiriam de um centro irradiador" (PEDRO, 2011, p.271). Também, de acordo com a autora, Anzaldúa faz um importante questionamento às feministas brancas e sob a noção de que são elas as inventoras dos questionamentos e enfrentamento da opressão sexista. Além disso, "pergunta por que elas não podem deduzir que as próprias mulheres não brancas, que vivem cada dia em situação opressiva, não possam adquirir consciência dessa política patriarcal e desenvolver estratégias de resistência por conta própria" (PEDRO, 2011, p. 275). E isso não é feminismo?

Ao reivindicar sua existência fronteiriça, Anzaldúa propõe olhar para o "céu feminista" com outra lente, denominado por Catherine Walsh (2007) como pensamiento propio latino-americano. A autora sugere uma perspectiva crítica que se diferencia do pensamento hegemônico dominante e "universal", que se difere, inclusive, de vertentes progressistas e de esquerda. Contudo, essa divergência, para Walsh (2007):

[...] não se destina a simplificar o pensamento indígena ou negro, ou relegá-lo à categoria ou estatuto de pensamento localizado, situado e culturalmente específico e concreto, isto é, como nada mais que 'conhecimento local' entendido como mera experiência. Pelo contrário, é apresentar seu caráter político e descolonial, permitindo uma conexão entre os vários pensamientos propios como parte de um projeto mais amplo de pensamento crítico e 'outros' conhecimentos (WALSH, 2007, p.231).
Nesse sentido, pensar a trajetória de mulheres que não tiveram suas experiências documentadas e reconhecidas através do tempo - que foi mediado por estruturas de poder - é pensar que suas lutas diárias ou organizadas, são lutas localizadas e não parte do feminismo. Se para Barros (2016), “problematizar é também aprofundar", talvez esse seja um ponto que precisa ser aprofundado dentro do conceito de feminismo, o que para Claudia de Lima Costa (2010) pode acontecer quando o feminismo trouxer para o centro "figuras tradutoras e traidoras de qualquer noção de original, de tradição, de pureza, de unicidade, binarismos, etc." (COSTA, 2010, p.56). De acordo com Barros (2016), "a função de "aprofundamento" implica ultrapassar os níveis de ingenuidade do senso comum". Neste caso, seria ultrapassar os níveis da epistemologia hegemônica, que não nos permite enxergar que no céu existam mais estrelas.

\section{Feminismo e decolonialidade: um conceito}

Será o feminismo um conceito ou uma noção? Para Barros (2016), uma das características dos conceitos é serem "dialógicos por dentro - através de uma rede articulada de sentidos que se interligam - e dialógicos por fora, através de uma riqueza de possibilidades de articulações com outros conceitos vizinhos ou distantes" (BARROS, 2016, p.31). Já as noções, de acordo com o autor, "são "quase conceitos", mas ainda funcionando mais como imagens de aproximação de um determinado objeto de conhecimento" (BARROS, 2016, p. 67). Ainda, conforme Barros (2016), é possível que "esta noção vá gradualmente se transformando em 'conceito' ao se adquirir na comunidade científica uma consciência maior dos seus limites, riquezas e potencialidades" (BARROS, 2016, p.67).

A partir disso, proponho pensar nos limites, riquezas e potencialidades da ideia de feminismo através de sua extensão e compreensão. Um feminismo "sem critério" seria inútil por sua característica generalizadora, pois "o conceito que reunisse em si todas as características de um objeto só serviria para a descrição desse único objeto, com exclusão de todos os demais, e de imediato, perderia o "potencial comparativo" que todo o conceito deve possuir (BARROS, 2016, p. 81). Ao passo que, reduzir o feminismo a uma ou outra experiência o limitaria a ponto de não ser capaz de dimensionar a ideia de 
"uma luta para erradicar os fundamentos e as causas culturais do sexismo e de outras formas de opressão social" (HOOKS, 2019, p.66). Essa definição dada por bell hooks, contradiz a explicação do conceito dado por Barros (2016), onde o machismo é para o feminismo "o par antagônico que o gerou como resistência", pois o feminismo não é o contrário de machismo, ele é uma luta por libertação em uma sociedade que oprime a partir de várias estruturas que se retroalimentam. O capitalismo, o patriarcado e a colonialidade são dessas estruturas que procuram fundar nossa racionalidade, inclusive, por vezes, a racionalidade feminista.

Chama-se "extensão" de um conceito precisamente ao grau de sua abrangência em relação a vários fenômenos e objetos; e chama-se "compreensão" de um conceito o esclarecimento das características que o constituem. De acordo com Barros (2016), "à medida que um conceito adquire maior "extensão", perde em "compreensão" [...] A interação entre a "compreensão" e a "extensão" de um conceito, portanto, baseia-se em uma relação inversa (BARROS, 2016, p.72). Assim, dentro da compreensão de uma luta para acabar com a opressão sexista, podemos incluir na extensão do conceito de feminismo por diversas vertentes, que entendem a opressão sexista por variados paradigmas interpretativos, neoliberais, marxistas, pós-estruturalistas, pós-coloniais, decoloniais, entre outros.

Françoise Vergès (2020), se propôs a analisar o que faz ideologias que, à primeira vista parecem destoar da ideia de feminismo, aderirem a esta palavra, como é o caso das ideologias liberais, nacionalistas, xenófabas e de extrema direita. De acordo com a autora, "o feminismo e as correntes nacionalistas xenófabas não proclamam objetivos comuns, mas compartilham pontos de convergência" (VERGÈS, 2020, p.27). Esses pontos de convergência nascem da ideia de uma modernidade a ser seguida, de um processo civilizatório que reproduz as estruturas fundantes das sociedades. Para Vergès (2020), "cumplices ativas da ordem capitalista racial, as feministas civilizatórias não hesitam em apoiar políticas de intervenção imperialistas, políticas islamofóbicas ou negrofóbicas" (VERGÈS, 2020, p.37).

Para os feminismos de política decolonial, reinventar a narrativa europeia é justamente contestar a ideologia ocidental-patriarcal e capitalista, que transformou categorias, como as mulheres, em "seres inferiores marcados pela ausência de razão" (VERGÈS, 2020, p.39). Dessa forma, se compreendermos o feminismo tal qual se expressa o decolonial, ou seja, a partir da ideia de acabar com a opressão sexista, mas também erradicar os fundamentos e as causas culturais do sexismo e de outras formas de opressão social. Da luta das mulheres que foi documentada, mas também a luta por qualquer forma de opressão patriarcal em qualquer etapa da história. Se compreendermos esse feminismo como um movimento de despatriarcalização das lutas revolucionárias, aumentaremos muito a sua compreensão, mas recuamos sua extensão, na medida que excluímos todos aqueles movimentos intitulados feministas, mas que não entendem a luta contra opressão como uma luta contra os sistemas dominantes. A esse feminismo, chamamos feminismo decolonial. E sua proposta metodológica é justamente se esforçar para que possamos, nesse céu tomado por poluições luminosas, enxergar o que não se vê.

Para Barros (2016), alguns conceitos compartilham determinadas características, mesmo que correspondam a fenômenos, objetos ou processos radicalmente distintos uns dos outros, "quase à maneira de dois acordes musicais que partilham de uma ou duas notas em comum embora seus efeitos sonoros sejam completamente diferentes em um caso e outro" (BARROS, 2016, p.50). Nesse sentido, o feminismo decolonial seria um outro conceito. De acordo com Vergès (2020):

Os feminismos de política decolonial rejeitam essas fórmulas que segmentam, pois eles se apoiam na longa história das lutas de suas antepassadas, mulheres autóctones durante a colonização, mulheres reduzidas à escravidão, mulheres negras, mulheres nas lutas de libertação nacional e de internacionalismo subalterno feminista nos anos 19501970, mulheres racializadas que lutam cotidianamente nos dias de hoje. (VERGÈS, 2020, p.36).

É importante, também, pensar nesse olhar para o feminismo considerando o que Barros (2016) chama de «anacronismo». Para ele, «a expressão 
〈anacronismo〉, ou 〈anacrônico〉 (〈fora do tempo〉), é empregada quando ocorre a utilização estranha ou inadequada de algo - em nosso caso de uma palavra - quando importada de um para outro tempo» (BARROS, 2016, p.146). Ainda, para ele, o anacronismo pode ocorrer movimentandose do passado para o presente ou do presente para o passado. No caso do feminismo, está muito mais ligado ao fato de encararmos a história a partir de uma perspectiva que não considera que «quase tudo o que existe como dado na historiografia atual [...] reflete o projeto social das elites dominantes (DIAS, 1994, p. 381).

Se para Barros (2016), “os conceitos transformam a própria história; não são apenas um produto dela” (BARROS, 2016, p. 64), para Dias (1994) “o acumular de conhecimentos específicos sobre a experiência concreta das mulheres em sociedades caracterizadas, como a nossa, pelo convívio de diferentes etnias e com grande desigualdade de renda, a longo termo, vem se contrapor aos valores culturais de dominação" (DIAS, 1994, p. 381). O conceito de feminismo decolonial justamente questiona a falta das diversas experiências de luta e resistência, de diversas mulheres, em diversos contextos e partes do mundo, que não foram documentados pela história e não fazem parte de um enunciado que as representa tanto, ou que elas representam tanto: o feminismo.

\section{Considerações finais}

O feminismo é dessas palavras que podem ser facilmente descontextualizadas. Pode se aliar com outras tantas, que fazem a sua prática apontar para diversas formas políticas/sociais. Por isso a importância da construção de uma ideia feminista decolonial, não apenas como posicionamento epistemológico, mas como via de pensar e repensar sua práxis, pois possui uma característica crítica.

Em teoria, considera a experiência de mulheres em diversos contextos, especialmente os que se inserem no cotidiano e na concretude de viver uma vida marcada pela ideia do que a modernidade construiu como "ser mulher". Assim, é feminismo acolher o filho que não é seu, mas que precisa de cuidados quando sua mãe precisa trabalhar; é feminismo cuidar da casa e lutar para que sua filha tenha uma trajetória diferente da sua; é feminismo reconhecer o trabalho de cuidado como trabalho; é feminismo andar em bando para nos protegermos à noite. É feminismo tudo aquilo que leva nossa condição individual a uma ideia de coletividade, não importa se de forma organizada, como dentro de movimentos sociais, ou de forma espontânea. Espontânea como as que compreendem a vida de muitas mulheres, que podem não se dizer feminista, não se reconhecer feministas e não serem reconhecidas como tal, mas que na sua práxis modificam a vida umas das outras.

Nesse sentido, o feminismo decolonial, se compreendido como um conceito, é capaz de dar conta de tais experiências e movimentar a amplidão do céu feminista para uma luta que comporte quem está às margens do que a racionalidade moderna projeta como agentes feministas. Uma agência que não se reconhece na ideia de rompante com a realidade posta, mas na capacidade de fissurar aquilo que as oprime.

\section{Referências}

BARROS, J. D. Os conceitos: seus usos nas ciências sociais. Petrópolis: Vozes, 2016.

CARNEIRO, M. E. R. Feminismo-feminismos. In: COLLING, A. M.; TEDESCHI, L. A. Dicionário crítico de gênero. Universidade Federal da Grande Dourados, 2019.

COSTA, C. L. Feminismo, tradução cultural e a descolonização do saber. Fragmentos: Revista de Língua e Literatura Estrangeiras, v. 21, n. 2, p. 4559, 2010.

DIAS, M. O. L. S. Novas subjetividades na pesquisa histórica feminista: uma hermenêutica das diferenças. Estudos feministas, p. 373-382, 1994.

FEDERICI, S. O ponto zero da revolução: trabalho doméstico, reprodução e luta feminista. São Paulo: Elefante, 2019.

FEMINISMO. In: DICIO, Dicionário Online Brasileiro da língua portuguesa. Melhoramentos: Michaelis, 2021. Disponível em: <https://michaelis. uol.com.br/busca?id=ZBWx>

GARGAGLiONI, S. Poluição luminosa e a necessidade de uma legislação. ComCiência, n. 112, p. 0-0, 2009.

GUIMARÃES, M. F. Trajetória dos feminismos: introdução a abordagem de gênero. In: CASTILLO-MARTIN, Márcia; OLIVEIRA, Suely de.(Orgs.) Marcadas a Ferro: violência contra a mulher. Brasília: Secretaria Especial de Mulheres, 2005. 
HOOKS, B. Teoria Feminista: da margem ao centro. São Paulo: Perspectiva, 2019.

MIGUEL, L. F. O feminismo e a política. In: BIROLI, F.; MIGUEL, L. F. Feminismo e política: uma introdução. Boitempo Editorial, 2015.

MIÑOSO, Y. E. Sobre porque é necessário um feminismo decolonial: diferenciação, dominação coconstitutiva da modernidade ocidental. São Paulo: Masp Afterhall, 2020.

PEDRO, J. M. Relações de gênero como categoria transversal na historiografia contemporânea. Topoi, Rio de Janeiro, v. 12, n. 22, p. 270-283, 2011.
TRUTH, S. E não sou eu uma mulher? Convenção pelos Direitos das Mulheres. Ohio, 1851. Disponível em: $<$ https://www.geledes.org.br/e-nao-souumamulher-sojourner-truth/>

VERGÈS, F. Um feminismo decolonial. São Paulo: Ubu editora, 2020.

WALSH, C. Shifting the Geopolitics of Critical Knowledge: Decolonial Thought and Cultural Studies "Others" in the Andes. Cultural Studies, 21.2-3, p.224-238, 2007. 